\title{
The Monolingual Nature of Speech Segmentation by Bilinguals
}

\author{
ANNe Cutler \\ MRC Applied Psychology Unit, 15 Chaucer Rd., Cambridge CB2 2EF, United Kingdom \\ JACQUES MEHLER \\ Laboratoire de Sciences Cognitives et Psycholinguistique, CNRS \& EHESS, \\ 54 Boulevard Raspail, 75006 Paris, France \\ DENNIS NORRIS
}

MRC Applied Psychology Unit, 15 Chaucer Rd., Cambridge CB2 2EF, United Kingdom

AND

Juan Segui

Laboratoire de Psychologie Expérimentale, associé au CNRS, 28 rue Serpente, 75006 Paris, France

\begin{abstract}
Monolingual French speakers employ a syllable-based procedure in speech segmentation; monolingual English speakers use a stress-based segmentation procedure and do not use the syllable-based procedurc. In the present study FrenchEnglish bilinguals participated in segmentation experiments with English and French materials. Their results as a group did not simply mimic the performance of English monolinguals with English language materials and of French monolinguals with French language materials. Instead, the bilinguals formed two groups, defined by forced choice of a dominant language. Only the French-dominant group showed syllabic segmentation and only with French language materials. The English-dominant group showed no syllabic segmentation in either language.
\end{abstract}

The authors contributed equally; names are listed in alphabetical order. This research was supported by grants from the European Training Programme in Brain and Behaviour Research of the European Science Foundation and from the Human Frontier Science Program. J.M. further acknowledges support from CNET. We are grateful for the cooperation of the staff and students of the Lycée Français, London, and the Ecole Active Bilingue (J.M.), Paris. A brief report of part of Experiments 1 and 2 appeared as a letter to Nature (London), 340, 229-230 (1989). We thank Sylvie Athènes, Jean-Luc Aucouturier, Sally Butterfield, John Culling, Emmanuel Dupoux, and Ruth Kearns for technical assistance; and François Grosjean for useful discussions. Reprint requests should be addressed either to the first author at MRC Applied Psychology Unit, 15 Chaucer Rd., Cambridge CB2 2EF, UK, or to the second author at Laboratoire des Sciences Cognitives et Psycholinguistique, 54 Boulevard Raspail, 75006 Paris, France. 
However, the English-dominant group showed stress-based segmentation with English language materials; the French-dominant group did not. We argue that rhythmically based segmentation procedures are mutually exclusive, as a consequence of which speech segmentation by bilinguals is, in one respect at least, functionally monolingual. (1) 1992 Academic Press, Inc.

\section{INTRODUCTION}

Bilingualism is not an absolute. Although in popular parlance the term may signify equal and perfect performance in more than one language, and, indeed, some researchers refer to "true" bilingualism (e.g., Thiery, 1976), in practice it is highly unlikely that a speaker who uses two languages will use each in exactly the same way. Much language use is taskand situation-specific, and language competency can be similarly varied.

Glaring examples of this can be found in technical vocabularies. It is easy to imagine a speaker who has apparently perfect command of two languages, but knows the technical vocabulary of a particular job in only one of them-say, a Belgian speaker of Flemish and French who goes to Paris to train as a chef. Conversely, it is just as easy to imagine another speaker whose mastery of a particular language is in general poor, but whose command of vocabulary and communicative competence in that language in a particular subject area are faultless-recall, for example, that the international language of air traffic control is English. However, variant competence may apply equally well to interactional modes, use of style and register, mastery of writing as well as speaking, and so on. Under these conditions it is impossible to set a firm criterion for what will and will not count as "true" or "perfect" competence in a language, so that it is in turn impossible to define the "true" or "perfect" bilingual.

For this reason, most recent researchers in the subject (e.g., Baetens Beardsmore, 1982; Grosjean, 1982) write in terms of degrees of bilingualism. Inasmuch as any of us can communicate in more than one language, we are to some degree bilingual.

Making use of more than one language means drawing on more than one linguistic resource in all the ways in which languages can differmore than one repertoire of words, of syntactic structures, of prosodic patterns, and so on. However, language-specificity is not restricted to differences in linguistic structure. There are, recent research has revealed, also language-specific aspects to linguistic processing, i.e., to the mental processes which operate upon the linguistic data in the course of, for instance, speech recognition.

The evidence for language-specific processing in recognition comes from studies of speech segmentation. Spoken utterances are continuous and contain few reliable word boundary cues. Nevertheless, memory representations must be discrete-we could not possibly store the infinite number of possible complete utterances we might hear. Thus to under- 
stand a spoken utterance, a listener must isolate individual words, and understanding continuous speech must therefore involve a process of segmenting the speech stream. Such speech segmentation procedures appear to differ across listeners as a function of native language. A segmentation procedure which is efficient for one language group, and is used by that group in speech processing, may be useless for another language, whose listeners rely on a quite different procedure.

Studies in our laboratories have confirmed that quite different segmentation procedures are used by native listeners of English and French. English speakers show evidence of segmenting speech at the onset of stressed (or, more exactly: strong) syllables. For instance, they find it difficult to detect a real word embedded in nonsense if the end of the embedded word forms the onset of a strong syllable (Cutler \& Norris, 1988); and their errors of segmentation are most likely to be ones which mistakenly take noninitial strong syllables to be word-initial, but mistakenly take initial weak syllables to be noninitial (Cutler \& Butterfield, 1992). This lexical segmentation strategy is highly effective for English because the great majority of English lexical words do in fact begin with strong syllables, i.e., syllables bearing primary or secondary stress (Cutler \& Carter, 1987). However, it is clear that such a procedure would be useless for a language like French, which has a prosodic structure quite different from the stress rhythm so characteristic of English. And indeed, the segmentation procedure used by French listeners is different from the English one: it is based on the syllable.

Evidence for this procedure comes from studies with the syllablemonitoring task, which have shown a consistent and robust effect with French-speaking listeners: responses are faster when the target to be detected corresponds exactly to a syllable in the word it occurs in. This effect was originally established by Mehler, Dommergues, Frauenfelder, and Segui (1981). Listeners in their experiment were presented with lists of spoken words and monitored within each list for a specified word-initial sequence of sounds. This target was either a consonant-vowel (CV) sequence such as $b a$ - or a consonant-vowel-consonant (CVC) sequence such as bal-. The words which contained the target had one of two syllable structures: the initial syllable was either open (CV), as in balance, or closed (CVC), as in balcon. Note that both balance and balcon begin with the same three initial sounds, so that subjects will appropriately make a positive response to either word given either $b a$ - or $b a l$ - as target. However, the syllable structure of the two words is such that each target is equal to a complete syllable in only one word: $b a$-is exactly equal to the first syllable of balance, but less than the first syllable of balcon, while $b a l$ - is exactly equal to the first syllable of balcon but more than the first syllable of balance. 
This correspondence determined response patterns in Mehler et al.'s experiment (1981). For balance-type words, responses to CV targets were faster than responses to CVC targets. For balcon-type words, however, responses to CVC targets were faster than responses to CV targets. Figure $1 \mathrm{~A}$ presents these results.

In English, however, no such syllabic correspondence effects appear. Cutler, Mehler, Norris, and Segui (1986) replicated the Mehler et al. (1981) study in English with English-speaking listeners using CV and CVC targets with English words like balance and balcony. Responses to balance-type words were faster than responses to balcony-type words, but there was no effect at all of target size (see Fig. 1B).

This result is not necessarily what would have been expected. Although it is true that, as we said above, the (stress-based) segmentation procedure proposed for English could not apply to French, there is no logical bar to applying the (syllable-based) French procedure to English. Not all languages have English-like stress, but all languages do have syllables; a
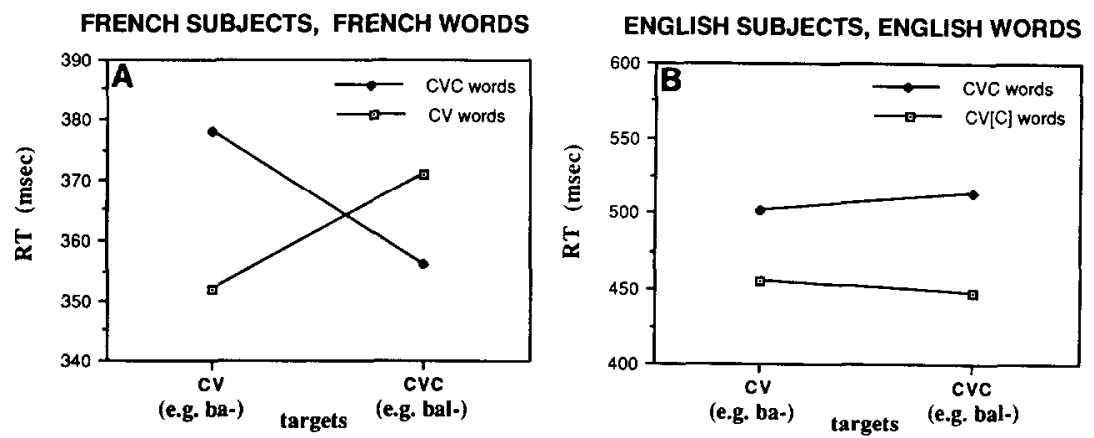

FRENCH SUBJECTS, ENGLISH WORDS


FIG. 1. Mean target detection response time (RT) in msec as a function of size of target sequence (CV, e.g., ba-, versus CVC, e.g., $b a l$-) and size of initial syllable of stimulus word (CV versus $\mathrm{CVC}$ for French; CV[C] versus CVC for English) in preceding studies, for four combinations of subjects' native language and stimulus presentation language: (A) French subjects and words; (B) English subjects and words; (C) French subjects, English words; (D) English subjects, French words. 
syllable-based segmentation procedure could be language-universal in a way a stress-based procedure never could. Why then do English listeners not use a segmentation procedure based on the syllable?

Cutler et al. (1986) proposed that syllabic segmentation would simply not be efficient for English. English rhythm is stress-based and, as is characteristic of stress languages, native speaker judgements show that some syllable boundaries are relatively unclear. This is especially true when a single consonant occurs at the boundary between a stressed vowel and a following unstressed vowel (as in balance); consonants in such position can be ambisyllabic, i.e., simultaneously part of both syllables. In French, in contrast, speech rhythm is syllablc-based, and native speaker judgements show that syllable boundaries are relatively unambiguous. Thus while segmenting speech into syllables would be relatively unproblematic in French, it could present much greater difficulties in English, and this in turn would make a syllabically based segmentation procedure unlikely, since such a procedure would not obviously enhance processing efficiency.

Differences in the phonological structure of the two languages, in other words, underlie differences in the processing procedures. The syllabic segmentation procedure is available to French listeners because it is efficient for the processing of French; English listeners do not use it because it would be inefficient for the processing of English. Interestingly, though, it is not the case that listeners who do use syllabic segmentation when the input language encourages it will then abandon it when the phonological structure of the input language discourages it. Cutler et al. (1986) conducted follow-up studies in which they presented English listeners with French words and French listeners with English words. English listeners still showed no sign of syllabic effects even when they were listening to easily syllabified French (Fig. 1D). French listeners presented with English, however, produced faster responses to $\mathrm{CV}$ targets in balance-type words than in balcony-type words, and faster responses to CVC targets in balcony-type words than in balance-type words (Fig. 1C); that is, they showed signs of syllabically based responding even when they were listening to speech in a language which does not encourage syllabic segmentation.

Further analysis of the results of this latter experiment, though, suggests that syllabic segmentation may not be the only resource available to French listeners. As Cutler et al. (1986) pointed out, it was only with one type of English word that the French listeners' responses were obviously syllable based. Words like balcony are clearly syllabified even in English (the first syllable being CVC); and as can be seen from Fig. 1C, the French listeners indeed responded significantly faster to CVC targets than to $\mathrm{CV}$ targets in these words. This response time advantage for CVC targets is clear evidence of a syllabic segmentation effect with these listeners (in contrast to the English speakers, who showed no such effect). 
With words like balance, however, which have an ambisyllabic consonant and hence are less easily syllabified, the French listeners' response times to CV and CVC targets were in fact not significantly different. This could imply that they were not successful in applying syllabic segmentation to these words. It was noticeable, though, that their response times to these words were not slower than to the balcony-type words, although slower responding would have been predicted had the listeners attempted to apply syllabic segmentation, without success, to words like balance.

Cutler et al. (1986) suggested that this apparent paradox could be resolved by postulating that the French listeners were applying two alternative segmentation procedures in parallel: syllabic segmentation, which resulted in faster responses whenever the target actually was equal to a syllable, and a nonsyllabic procedure, which was unaffected by the syllabic status of the target.

If so, it may be the case that more than one segmentation procedure is available to all listeners. However, such procedures may fall into two classes: those which are available to all language users, and those which have restricted availability because they depend on appropriate phonological input for their development. Syllabic segmentation, developed by language users who have grown up speaking French but not by those who have grown up speaking English, would belong to the latter, restricted class. Stress-based segmentation, likewise, would have restricted availability because it would be developed only by language users who have grown up speaking a stress language - thus it would be available to English speakers but not to French speakers. The procedures with restricted availability would develop in parallel to the nonrestricted speech processing procedures developed by all language users; in each language, the restricted procedure would be used to enhance the efficiency of spcech segmentation, but its use would not be necessary, in that the more general processes would always also be available. For example, the general procedures would be what French listeners would presumably fall back on to process English words like balance.

The notion of restricted-availability procedures has considerable theoretical importance because of its claim that the human language processor has language-specific aspects to its development. The processing of a particular language is not, in general, considered psycholinguistically interesting in itself; the proper object of psycholinguistic enquiry is the human language processor, and evidence from the processing of a particular language is primarily of interest in so far as it sheds light on the structure of the processor itself. Thus psycholinguists aim for a model of the human processor, not a model of any particular human's processor. It is assumed that the human language processor does not start out equipped with language-specific features; any infant can, given the appropriate in- 
put, acquire any natural human language. But the results of the FrenchEnglish comparison suggest that the nature of the input language during development interacts with the nature of the development process to determine which particular processing procedures are developed. That is, language acquisition involves inter alia the development of segmentation procedures; but the specific characteristics of these procedures are not determined in the prelinguistic processor.

However, there is definitely symmetry in comparing a stress-based procedure for English with the French speakers' syllabic segmentation, because in both cases there is an intimate connection with the basic rhythmic structure of the languagc. The rhythm of English is stress-based, and stress is the basis of a segmentation procedure used by English speakers; the rhythm of French is syllable-based, and French speakers use syllabic segmentation. It is an intriguing possibility, therefore, that the human language acquisition system contains a routine for development of a procedure to assist speech segmentation specifically by exploiting rhythmic structure. This process might be conceived as determining what in the linguistic input is the basis of rhythm-i.e., at what level is the smallest occurring regularity. Perceptual processing routines could then be adapted so as to exploit as efficiently as possible the regularity at this particular level. Because the basis of linguistic rhythm varies across languages, so therefore will segmentation procedures vary. If the input is in a language in which the smallest occurring regularity is the syllable, speakers will develop the ability to use syllabic segmentation. If however the smallest occurring regularity in the input language is at some level other than the syllable, syllabic segmentation will not be developed; but some alternative procedure will be. If the smallest occurring rhythmic regularity is the stress unit, for example, the segmentation procedure which is developed will be stress-based. Thus language-specificity would be limited, in that all language users would develop a segmentation procedure to exploit rhythmic regularity; but the type of procedure which was developed would vary.

This picture of language acquisition strongly suggests that the acquisition system is set up to develop one segmentation procedure only. But is this true? In the present study we attempt to answer this question. To do so, we turned to the crucial test case: bilinguals. Do those who grow up acquiring more than one language also develop more than one segmentation procedure? In particular, what happens if two languages which are simultaneously acquired have fundamentally different rhythm? For instance, do those who grow up simultaneously acquiring both French and English develop syllabic segmentation, or stress-based segmentation, or both, or neither?

We chose to test subjects who, in the framework of degrees of bilin- 
gualism, were as bilingual as we could find. To all intents and purposes they had equally perfect command of both English and French. Our primary criteria in selecting subjects were: native competence as assessed by other native speakers of each language, early acquisition of both languages, and regular use of both languages.

Clearly it is not possible to conduct a single experiment which will determine what segmentation procedure or procedures may be available to a given language user. The evidence for the procedures which have been proposed for English and French, for instance, comes from quite different experimental paradigms. The most desirable way to establish whether or not bilinguals command a particular procedure is to replicate, with bilingual subjects, exactly the experimental situation which led to the proposal of that procedure for monolinguals. This was therefore the approach which we adopted. We first addressed the question of syllabic segmentation. Experiments 1 and 2 constitute a direct comparison with our previous studies with monolinguals by exactly replicating with these bilingual listeners each of the earlier syllable-monitoring experiments.

We can envisage several possible patterns of results. First, it is possible that the bilinguals will perform like English monolinguals when listening to English and like French monolinguals when listening to French; the results for the group would in that case look like Figs. 1A and 1B. On the other hand, it is also possible that only one rhythm-based segmentation procedure can be developed and there is an inherent hierarchy among the alternatives such that (a) syllabic segmentation is always developed in preference to any alternative, if the input facilitates it, or (b) any alternative rhythm-based segmentation procedure will always take precedence over syllabic segmentation. In the case of (a), the results for the group would resemble Figs. $1 \mathrm{~A}$ and $\mathrm{IC}$; in the case of (b), they would resemble Figs. 1B and 1D. Finally, it is possible that only one such procedure may be developed and that which procedure it is may depend on some external factor such as the language of the parents or the language to which the speaker is more extensively exposed. In that case we would expect to find two subgroups among our subjects, with the results of one group resembling Figs. $1 \mathrm{~A}$ and $1 \mathrm{C}$ and the results of the other group resembling Figs. $1 \mathrm{~B}$ and $1 \mathrm{D}$.

\section{EXPERIMENTS 1 AND 2}

\section{Method}

Subjects. We established very strict criteria for the selection of subjects. The primary criterion was that each subject should be accepted as a native speaker of French by other speakers of French and should be accepted as a native speaker of English by other speakers of English. Since most of our subjects were tested in high schools, we asked the teachers to 
select students who met this criterion. In addition, the recordings made at the time of the experiment (see below) were reviewed by the authors and by colleagues native in French (in the English laboratory) and English (in the French laboratory), respectively; in no case did any subject sound other than completely native in both languages.

Additional criteria were that subjects should be using both languages on an everyday basis at the time of testing (easily satisfied by the students in bilingual high schools where daily use of both languages was a requirement), and that they should have been exposed to both languages simultaneously from 1 year of age or earlier.

Such subjects are, needless to say, not easy to find; we set as a target 12 subjects in England and 12 in France. We succeeded in testing 14 in each country. Most were young adults and were final year students in bilingual high schools in London and Paris; others were individuals located by personal contact.

Unsurprisingly, the majority of our subjects had one native French-speaking and one native English-speaking parent ( 21 of the 28 subjects).

Those subjects who were tested in England were paid a small honorarium for taking part in the experiment.

Materials. In order to achieve strict comparability with our previous results we used exactly the same experimental tapes as in the predecessor studies. Experiment 1, the French experiment, used the tape constructed by Mehler et al. (1981; Experiment 1), and Experiment 2, the English experiment, used the tape constructed by Cutler et al. (1986: Experiment 1).

The French experiment contained 20 experimental word lists and 20 distractor lists and was preceded by five practice lists. Lists varied in length from one to six items; the experimental items always occurred in final position, preceded by one, two, three, or four filler items. The experimental target words were balance, balcon, palace, palmier, carotte, carton, garage, gardien, tarif, tartine. These items form five pairs, and within each pair both items begin with the same CVC sequence but this sequence is differently distributed across syllables: in one item, the first syllable is the initial CV while in the other it is the whole CVC. Thus the pair balance-balcon each begin with the same three phonemes, but the first syllable of balance is $b a-$, while the first syllable of balcon is bal-.

The English experiment contained 28 experimental word lists and 28 distractor lists and was preceded by 10 practice lists. List length and target position were varied in the same manner as in the French experiment. Each experimental list contained as a final item one of the set balance, balcony, palace, palpitate, galaxy, galvanize, salad, salvage, talon, talcum, malady, malcontent, calorie, calculate. Again, the items form pairs, and within each pair one item begins with a $\mathrm{CV}[\mathrm{C}]$ syllable (where $[\mathrm{C}]$ represents an ambisyllabic consonant, i.e., a consonant which belongs simultaneously to two syllables) while the other begins with a CVC syllable. Thus both balance and balcony begin with the same three phonemes, but the [1] in balance is ambisyllabic, making the syllable boundary unclear, while balcony has a clear syllable boundary after the [I]. Note that the postvocalic [r] used in the French materials could not be used in the English materials because in standard British English [r] does not occur in preconsonantal position (thus party is pronounced [pa:ti]).

For each experimental word in each experiment there were two potential targets, corresponding to the word's initial $\mathrm{CV}$ and $\mathrm{CVC}$, respectively. As each experimental word occurred twice on the relevant experimental tape (once in the first half of the experiment, once in the second), subjects responded to both targets in each case. Therefore there were two orders of target presentation in order to control for order of target-item pairings (no order effects were found in any of the earlier studies). Thus for balance in each experiment half the subjects responded first to BA- and later to BAL-, while the other half responded first to BAL- and later to BA-. List length, experimental item position in lists, and position of distractor sequences with and without target occurrences were matched across the first and second half of each experiment. 
In each experiment half the distractor lists contained no item which matched the target specified for the list, while half contained a matching item in a position not used for experimental items. Each target occurred four times in each experiment: twice on experimental lists, once on a distractor list with target match, and once on a distractor sequence without target match.

Procedure. For each subject, we recorded a sample of speech in French and in English (in each case in interaction with an interlocutor native in the language in question). We also ascertained the native language of each parent. Finally, we attempted to establish a language preference for each subject. All subjects averred that they spoke both languages equally happily and refused to express a simple preference (although they sometimes claimed to prefer French for some purposes but English for other purposes). Accordingly we devised the following question: "Suppose you developed a serious disease, and your life could only be saved by a brain operation which would unfortunately have the side effect of removing one of your languages. Which language would you choose to keep?'" Subjects were instructed to ignore utilitarian factors and to answer this question purely according to preference.

Each subject took part in both Experiment 1 (French) and Experiment 2 (English). The tapes were presented binaurally over headphones, and the targets were presented visually prior to each list (in England the targets were presented on the screen of a VDU; in France they were presented on cards). Timing and response recording was under the control of a computer (a minicomputer in the case of those subjects who were tested in our laboratories; a portable microcomputer in the case of those subjects who were tested in their schools).

Order of presentation of the two experiments and target presentation order were counterbalanced within each of the subject sets (England and France). The subjects were instructed to listen within each list for a word beginning with the sound sequence designated as target for that list and to respond by pressing the response key in front of them as quickly as possible when such a word was detected.

\section{Results}

Overall analysis. Since the results are most meaningfully analyzed by comparison with the earlier results for the whole series of monolingual experiments, we report the results for the English and French experiments together. In our earlier studies, we had omitted all responses shorter than $100 \mathrm{~ms}$ or longer than $1 \mathrm{~s}$; we had also dropped any subject who missed or failed to respond within 1 s to more than $25 \%$ of experimental items on any tape. Application of the same criteria to analysis of the present data resulted in one subject's data being discarded and a further 18 responses (all of them long responses) being omitted. There were 28 occasions on which subjects failed to respond, so that missing data comprised $3.4 \%$ (44 of 1296) of all analyzed responses. The missing data points were distributed across all target-word-type combinations, and no patterns appeared except that more data points were missing in the English experiment (4.1\%) than in the French experiment $(2.4 \%)$, presumably because the English experiment was rather longer and more fatiguing.

Mean response times for each item and each subject were computed, and for each experiment two analyses of variance, with subjects and with 
items as random factors, were conducted. Below we report only those results which were significant in both analyses.

The aspect of interest in the present results is the extent to which they resemble the results of our previous studies. In one respect there is an obvious resemblance: the response times to the English words are longer than those to the French words, just as they were in the earlier studies. (This again presumably reflects the fact that the English experiment is rather longer and more fatiguing than the French one; also the rate of item presentation was somewhat slower than in the French experiment.) The most interesting aspect of the previous studies, however, was the difference in the effects of the word type and target size variables: French monolinguals, in both French and English experiments, produced no significant main effect of either word type or target size, but a significant interaction between these two factors; English monolinguals, on the other hand, produced in both experiments a main effect of word type only (Fig. 1).

The results for the group of 27 subjects as a whole are presented, separately for the French and English experiments, in Fig. 2. By com-


FIG. 2. Mean target detection response time (RT) in msec as a function of size of target sequence (CV, e.g., ba-, versus CVC, e.g., bal-) and size of initial syllable of stimulus word (CV versus $\mathrm{CVC}$ for French; $\mathrm{CV}[\mathrm{C}]$ versus $\mathrm{CVC}$ for English) in Experiments 1 and 2, for the 27 bilingual subjects as a group with (A) French words, and (B) English words. 
parison with Fig. 1 it can be seen that the pattern for the English words somewhat resembles the pattern produced by English monolingual subjects with these materials, in that the lines for each word type are parallel; but the lines are sloping rather than flat. However, the pattern for the French words resembles neither monolingual group's performance in the previous studies.

The results of the analyses of variance showed that neither for the English nor for the French words did the bilingual group as a whole produce results analogous to those produced by either monolingual group in the previous studies. With the English words, there is an effect of word type: balance-type words are responded to faster than balcony-type words $[F 1(1,26)=28.35, p<.001 ; F 2(1,12)=19.72, p<.001]$. However, there is also an effect of target size: CVC targets are detected more rapidly than $\mathrm{CV}$ targets $[F 1(1,26)=4.59, p<.05 ; F 2(1,12)=7.07, p<$ .03]. The effects do not interact. With the French words, no main effects or interactions reached significance.

Comparison with the previous findings, therefore, presents a puzzling picture. In a sense the results are more like those previously produced by English monolinguals; but the resemblance is far from perfect. With the English materials there is an effect of target size which we have never observed before; with the French materials, the pattern of converging lines is again unlike previously observed patterns. Since this overall analysis therefore left us with no obvious point of departure for interpretation of the bilingual results, we decided to look further for a reflection of our previous findings by subdividing our group. The data which we had collected allowed four such subdivisions: by country of current residence, by language of father and of mother, and by their answer to the question we had posed about language preference.

Subanalysis 1: Country of residence. Since the rejected subject was one of those tested in England, there were 13 subjects from England in this analysis and 14 from France. The mean RTs are shown in Table 1. The analysis of variance for the English words showed a significant word type effect for both groups $[F 1(1,12)=22.26, p<.001, F 2(1,12)=9.88, p<$ .01 for subjects in England, $F 1(1,13)=8.79, p<.02, F 2(1,12)=4.73, p$ $=.05$ for subjects in France], and a target size effect for subjects in France $[F 1(1,13)=4.61, p=.051, F 2(1,12)=13.64, p<.005]$. For the French words, no effects reached significance for either subject group. Again, resemblance to previous findings is hardly satisfying.

Subanalysis 2: Father's language. For obvious sociological reasons, there was a strong overlap between country of current residence and the language spoken by the subject's father (they matched for 22 of the 28 subjects). In this analysis there were 15 subjects with English-speaking fathers and 12 subjects with French-speaking fathers. The mean RTs are 
TABLE 1

\begin{tabular}{|c|c|c|c|c|}
\hline & \multicolumn{2}{|c|}{ French experiment } & \multicolumn{2}{|c|}{ English experiment } \\
\hline & $\begin{array}{c}\text { CV words } \\
\text { (e.g., balance })\end{array}$ & $\begin{array}{l}\text { CVC word } \\
\text { (e.g., balcon) }\end{array}$ & $\begin{array}{l}\text { CV }[\mathrm{C}] \text { words } \\
\text { (e.g., balance) }\end{array}$ & $\begin{array}{c}\text { CVC words } \\
\text { (e.g., balcony) }\end{array}$ \\
\hline \multicolumn{5}{|c|}{ Subjects in France } \\
\hline $\begin{array}{l}\text { CV targets } \\
\quad(\text { e.g., ba-) }\end{array}$ & 445 & 476 & 509 & 554 \\
\hline $\begin{array}{r}\text { CVC targets } \\
\text { (e.g., bal-) }\end{array}$ & 456 & 455 & 493 & 525 \\
\hline \multicolumn{5}{|c|}{ Subjects in England } \\
\hline $\begin{array}{l}\text { CV targets } \\
(\text { e.g., ba-) }\end{array}$ & 462 & 491 & 505 & 551 \\
\hline $\begin{array}{r}\text { CVC targets } \\
\text { (e.g., bal-) }\end{array}$ & 467 & 477 & 482 & 554 \\
\hline
\end{tabular}

Note. RT (msec) in each experiment as a function of size of target sequence and size of initial syllable of stimulus word, for subjects resident in France $(N=14)$ and in England $(N=13)$.

shown in Table 2. The analysis of variance for the English materials showed a significant word type effect for subjects with English-speaking fathers only $[F 1(1,14)=25.32, p<.001 ; F 2(1,12)=16.29, p<.005]$, and a target size effect for this group also $[F 1(1,14)=4.65, p<.05 ; F 2(1,12)$ $=6.25, p<.03]$. Subjects with French-speaking fathers showed no significant effects. For the French materials there were no significant effects for either group. This subanalysis produced results, therefore, which were quite unlike previous findings.

Subanalysis 3: Mother's language. Nine of our subjects had Englishspeaking mothers and 18 had French-speaking mothers. The mean RTs are shown in Table 3. For the English materials, both groups produced a

TABLE 2

\begin{tabular}{|c|c|c|c|c|}
\hline & \multicolumn{2}{|c|}{ French experiment } & \multicolumn{2}{|c|}{ English experiment } \\
\hline & $\begin{array}{c}\text { CV words } \\
\text { (e.g., balance) }\end{array}$ & $\begin{array}{c}\text { CVC word } \\
\text { (e.g., balcon) }\end{array}$ & $\begin{array}{l}\text { CVIC] words } \\
(\text { e.g., balance })\end{array}$ & $\begin{array}{c}\text { CVC words } \\
\text { (e.g., balcony) }\end{array}$ \\
\hline \multicolumn{5}{|c|}{ Subjects with French-speaking fathers } \\
\hline $\begin{array}{l}\text { CV targets } \\
\quad(\mathrm{e} . \mathrm{g} ., \text { ba-) }\end{array}$ & 461 & 487 & 508 & 542 \\
\hline $\begin{array}{l}\text { CVC targets } \\
\text { (e.g., bal-) }\end{array}$ & 478 & 478 & 499 & 532 \\
\hline \multicolumn{5}{|c|}{ Subjects with English-speaking fathers } \\
\hline $\begin{array}{l}\text { CV targets } \\
\text { (e.g., ba-) }\end{array}$ & 447 & 481 & 506 & 561 \\
\hline $\begin{array}{l}\text { CVC targets } \\
(\text { e.g., bal-) }\end{array}$ & 448 & 455 & 479 & 544 \\
\hline
\end{tabular}

Note. RT (msec) in each experiment as a function of size of target sequence and size of initial syliable of stimulus word, for subjects with French-speaking $(N=12)$ and English-speaking $(N=15)$ fathers. 
significant word type effect $[F 1(1,8)=5.98, p<.05, F 2(1,12)=11.38, p$ $<.01$, for subjects with English-speaking mothers, $F 1(1,17)=22.87, p<$ $.001, F 2(1,12)=9.66, p<.01$ for subjects with French-speaking mothers]. For the French materials, neither group showed any significant effects [although subjects with French mothers produced a significant crossover interaction between word type and target size in the items analysis only: $F 2(1,8)=6.87, p<.03$ ].

The results of this analysis for the English materials approximate more closely to our previous findings than those of any other subanalysis so far. However, the replication is far from perfect in the French experiment. Thus a pattern mimicking previous results has still not been achieved.

Subanalysis 4: Dominant language. For our final subanalysis we defined "dominant" language as the language named by each subject in the enforced answer to our question about preference. Twelve subjects chose French in answer to this question; 15 chose English. The mean RTs are shown in Table 4. The analysis of variance for the English words produced a significant effect of word type for both dominance groups $[F 1(1,14)=21.26, p<.001, F 2(1,12)=31.4, p<.001$ for the Englishdominant, $F 1(1,11)=8.03, p<.02, F 2(1,12)=4.39, p=.058$ for the French-dominant] and no other main effects or interactions. For the French words, however, the two groups differed: the English-dominant subjects again produced a significant word type effect $[F 1(1,14)=10.09$, $p<.01 ; F 2(1,8)=5.93, p<.05]$, while the French-dominant subjects produced no main effects but a significant interaction between word type and target size $[F 1(1,11)=6.62, p<.03 ; F 2(1,8)=10.14, p<.02]$.

With this analysis we find in each subset a clear reflection of the results shown by some previous group. Figure 3 captures the similarities. The

TABLE 3

\begin{tabular}{|c|c|c|c|c|}
\hline & \multicolumn{2}{|c|}{ French experiment } & \multicolumn{2}{|c|}{ Fnglish experiment } \\
\hline & $\begin{array}{c}\text { CV words } \\
\text { (e.g., balance) }\end{array}$ & $\begin{array}{l}\text { CVC word } \\
\text { (e.g., balcon) }\end{array}$ & $\begin{array}{c}\mathrm{CV}[\mathrm{C}] \text { words } \\
\text { (e.g., balance) }\end{array}$ & $\begin{array}{c}\text { CVC words } \\
\text { (e.g., balcony) }\end{array}$ \\
\hline \multicolumn{5}{|c|}{ Subjects with French-speaking mothers } \\
\hline $\begin{array}{l}\text { CV targets } \\
(\text { e.g., ba-) }\end{array}$ & 451 & 487 & 507 & 556 \\
\hline $\begin{array}{r}\text { CVC targets } \\
\text { (e.g., bal-) }\end{array}$ & 480 & 470 & 489 & 540 \\
\hline \multicolumn{5}{|c|}{ Subjects with English-speaking mothers } \\
\hline $\begin{array}{r}\mathrm{CV} \text { targets } \\
\text { (e.g., ba-) } \\
\text { CVC targets } \\
(\text { e.g., bal }-)\end{array}$ & 458 & 476 & 508 & 546 \\
\hline
\end{tabular}

Note. RT (msec) in eaclı experiment as a function of size or larget sequence and size of initial syllable of stimulus word, for subjects with French-speaking $(N=18)$ and English-speaking $(N=9)$ mothers. 
TABLE 4

\begin{tabular}{|c|c|c|c|c|}
\hline & \multicolumn{2}{|c|}{ French experiment } & \multicolumn{2}{|c|}{ English experiment } \\
\hline & $\begin{array}{c}\text { CV words } \\
\text { (e.g., balance })\end{array}$ & $\begin{array}{l}\text { CVC word } \\
\text { (e.g., balcon) }\end{array}$ & $\begin{array}{c}\text { CV[C] words } \\
\text { (e.g., balance) }\end{array}$ & $\begin{array}{c}\text { CVC words } \\
\text { (e.g., balcony) }\end{array}$ \\
\hline \multicolumn{5}{|c|}{ French-dominant subjects } \\
\hline $\begin{array}{l}\text { CV targets } \\
\text { (e.g., ba-) } \\
\text { CVC targets }\end{array}$ & 486 & 530 & 562 & 596 \\
\hline (e.g., bal-) & 521 & 494 & 538 & 586 \\
\hline \multicolumn{5}{|c|}{ English-dominant subjects } \\
\hline $\begin{array}{l}\text { CV targets } \\
\quad(\text { e.g., } b a-)\end{array}$ & 427 & 446 & 464 & 518 \\
\hline $\begin{array}{l}\text { CVC targets } \\
\text { (e.g., bal-) }\end{array}$ & 413 & 443 & 448 & 501 \\
\hline
\end{tabular}

Note, RT (msec) in each experiment as a function of size of target sequence and size of initial syllable of stimulus word, for French-dominant $(N=12)$ and English-dominant $(N=15)$ subjects.

English-dominant subjects produce exactly the pattern of results shown by English monolinguals, both with English and with French words. The French-dominant subjects produce results exactly like those of English monolinguals when they are listening to English words, but exactly like those of French monolinguals when they are listening to French words.

A post-hoc analysis of the missing data, splitting the subjects by language dominance, further confirms the relevance of this factor. In the English experiment, French-dominant subjects missed, or made long responses to, 20 items in all (5.95\%), while for English-dominant subjects only 11 data points were missing $(2.62 \%)$. In the French experiment, the reverse was true: there were 9 missing data points for English-dominant subjects (3\%), but only $4(1.67 \%)$ for French-dominant subjects. The interaction was significant $\left[\chi^{2}(1)=4.23, p<.05\right]$.

Finally, it can be seen that in general the English-dominant subjects respond rather faster than the French-dominant subjects. We attribute this to the fact that the mean age of the English-dominant group was lower than that of the French-dominant group. Note, however, that within each group the relationship between the French and English experiments is exactly preserved. Just as in the subject sample as a whole, for both subgroups the RT advantage for the French over the English experiment is just over $5.5 \%$ of the group mean.

\section{Discussion}

The results show a clear pattern, albeit not one of the clear patterns we had envisaged.

The first of the three patterns we suggested as possible outcomes of Experiments 1 and 2 was that the bilinguals would perform like English 


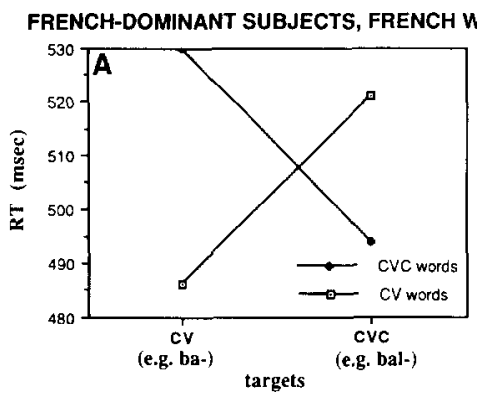

FRENCH-DOMINANT SUBJECTS, ENGLISH WORDS

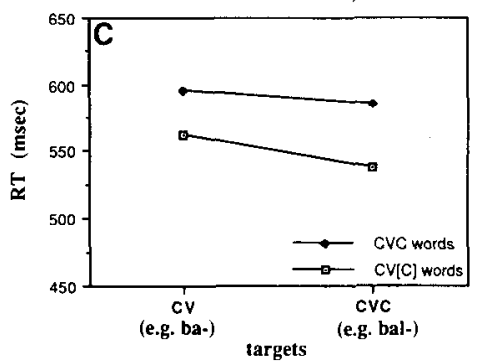

ENGLISH-DOMINANT SUBJECTS, ENGLISH WORDS

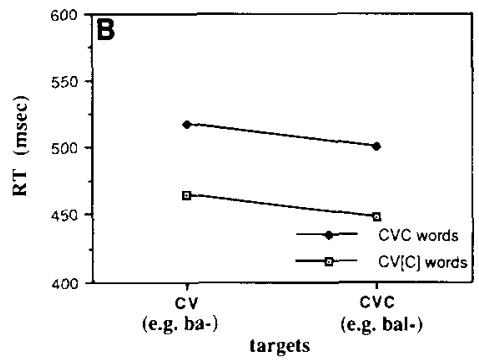

ENGLISH-DOMINANT SUBJECTS, FRENCH WORDS



FIG. 3. Mean target detection response time (RT) as a function of size of target sequence (CV, e.g., $b a-$, versus CVC, e.g., bal-) and size of initial syllable of stimulus word (CV versus CVC for French; CV[C] versus CVC for English) in Experiments 1 and 2, for four combinations of subjects' dominant language and stimulus presentation language: (A) French-dominant subjects and French words; (B) English-dominant subjects and English words; (C) French-dominant subjects, English words; (D) English-dominant subjects, French words.

monolinguals when listening to English and like French monolinguals when listening to French. Figure 2 should then have resembled Figs. 1A and $1 \mathrm{~B}$. This was clearly not the case. Thus our results provide further support for Grosjean's (1989) claim that "the bilingual is not two monolinguals in one person."

Second, we suggested that syllabic segmentation might prove either to be necessarily dominant or necessarily nondominant, so that the performance of the whole group would mimic that of one or the other monolingual group. Figure 2 would then have looked like Figs. 1A and 1C, or like Figs. 1B and 1D. Again, this is clearly not the case, from which we may conclude that the syllabic segmentation procedure used by French monolinguals does not necessarily dominate, but is also not necessarily dominated by, the procedures used by English monolinguals.

Third, we suggested that our subjects might fall into two groups, one of which would produce a response pattern similar to Figs. $1 \mathrm{~A}$ and $1 \mathrm{C}$, while the other produced a response pattern similar to Figs. IB and 1D. Indeed, 
we did find two subgroups among our subjects; when a division was made according to "dominant" language, the results of the two groups that were formed resembled results found with the monolingual subjects of our earlier studies. Moreover, one of the subgroups produced a response pattern like Figs. 1B and 1D-that is to say, they performed as English monolinguals do with these materials. The other group, however, produced a pattern resembling Figs. 1A and $1 \mathrm{D}$ rather than 1A and $1 \mathrm{C}$; that is, they performed like French monolinguals when they were listening to French, but like English monolinguals when they were listening to English.

It is the pattern of results for nondominant language processing which most demands explanation. With their dominant languages each group performed just like monolinguals; but with the nondominant languages the two groups behaved quite differently. The English-dominant group produced responses to French which were just like the responses of English monolinguals, i.e., with their nondominant language they behaved like monolingual speakers of their dominant language. The French-dominant group, on the other hand, produced responses to English which were like those of English monolinguals, i.e., with their nondominant language they behaved like monolingual speakers of their nondominant language.

In other words, the French-dominant subjects appear more flexible-in a sense, more bilingual-than the English-dominant group; they can use monolingual-like procedures with both their dominant and nondominant languages, while the English-dominant group use monolingual-like procedures with their dominant language only.

In terms of the use of syllabic segmentation, the asymmetry is similar. Clearly, the French-dominant subjects do use syllabic segmentation: their responses to French stimuli looked just like the responses produced by French monolinguals. But they do not use syllabic segmentation with English words. The English-dominant subjects, however, fail to use syllabic segmentation at all, even though they have, just like monolingual French speakers, been exposed to French all their lives, and even though its use is highly efficient with French.

We suggest that the explanation for these asymmetries lies in the distinction which we introduced in the introduction, between procedures which are available to all language users and procedures which are available only upon exposure to certain features in the language input. We further suggested there that the pattern of results which we found in our earlier studies with monolinguals would indicate that syllabic segmentation is a procedure of the restricted rather than the general kind.

The results of Experiments 1 and 2 are indeed compatible with such a view. To explain the pattern of results shown by the French-dominant group, it is only necessary to add to the distinction between general and 
restricted procedures the further proposal that any restricted procedure can be optional, in the sense that its use can be "switched off" when and if it fails to be efficient. French-dominant bilinguals have developed the syllabic segmentation procedure because it is inefficient for processing their dominant language. But with extensive exposure to language input with which syllabic segmentation is often inefficient-i.e., English-these bilinguals have also learned not to employ the procedure at all with such input because it fails to produce significant and consistent processing advantages.

Note that although monolingual French speakers are hypothetically also able to switch off syllabic segmentation when presented with input for which its use is inefficient, we would not expect them to do so. Efficiency of such procedures can only be estimated in the light of the ends for which they presumably exist, namely, the facilitating of lexical access. A monolingual cannot by definition perform lexical access with foreign language input; such input is essentially a stream of nonwords, and no amount of exposure to nonwords will provide evidence for the efficiency or otherwise of a language processing procedure. If we, then, cause a monolingual to perform segmentation with foreign language input, we would expect native language procedures to be applied irrespective of their relative efficiency. Indeed, our earlier studies with monolinguals showed that French monolinguals continue to use syllabic segmentation, where applicable, even when they are presented with English input.

It now remains to be explained why the English-dominant group failed to use syllabic segmentation with French input. We assume that a restricted procedure can only be developed when the dominant language (which for a monolingual, of course, will be the only language) encourages its use. If the dominant language does not encourage development of a particular restricted procedure, the procedure cannot be developed, which in turn obviously means it can't be "switched on" by input which would encourage its use, no matter how much of such input may be presented. Restricted procedures can be switched off but not on; those who have developed the restricted procedure also have the general procedure available to them, but the reverse is not the case. In other words, the English-dominant group failed to use syllabic segmentation with French simply because they do not have this procedure available to them at all; they do not have it available because their dominant language, English, does not encourage its development.

We suggested in the Introduction also that the segmentation procedure which English does encourage is one based on stress. Thus we would expect that French-English bilinguals whose dominant language is English would have developed stress-based segmentation. However, the syllable-monitoring studies provide no evidence relevant to stress-based segmentation. All the targets in these experiments occur in word-initial 
position, the words are presented in isolation rather than in running speech, and all the target words have the same stress pattern: strong first syllables and weak second syllables. Stress-based segmentation would not play a role in these experiments, since the materials offer no opportunity for it to be applied; it has to be assumed, therefore, that the responses of English monolinguals and of English-dominant bilinguals reflect only the operation of generally available processing procedures, rather than of restricted procedures which particularly facilitate segmentation. Likewise, when French-dominant bilinguals are presented with input in their nondominant language and "switch off" syllabic segmentation, what they use in its place will be the generally available procedure. (Small wonder, then, that their responses with English look just like the responses of English monolinguals.)

To establish whether the English-dominant bilinguals have indeed developed stress-based segmentation, it is necessary to test them in an experimental situation in which monolinguals have been shown to produce stress-based responses. An appropriate procedure to employ for such a test is the word-spotting task used by Cutler and Norris (1988). Cutler and Norris presented listeners with nonsense bisyllables and asked them to respond to any bisyllable which began with a real word. The crucial set of embedded words in their experiments had the form CVCC and were converted to nonsense by the addition of a final VC sequence, in which the vowel could be either strong or weak. Thus mint was embedded in [mintef] ("mintayf') and [mintəf] ("mintef'). Cutler and Norris found that detection of the embeded word was inhibited in the case where the following vowel was strong-i.e., mint took longer to detect in mintayf than in mintef. They attributed this finding to a segmentation heuristic which is based on the high probability that English lexical words will begin with strong syllables (Cutler \& Carter, 1987); listeners have learned to exploit this probability by using the heuristic procedure of segmenting speech signals at strong syllable onsets in the expectation that strong syllable onsets will also be the onsets of new words. As Cutler and Butterfield (1992) showed, further evidence for the use of this heuristic appears in listeners' missegmentations of continuous speech.

Note, however, that there is an asymmetry in comparing the previous studies of stress-based and syllable-based segmentation, in that although we have shown that English monolinguals fail to use syllabic segmentation, we have not shown that French monolinguals fail to use stress-based segmentation. For instance, Cutler and Norris' study has not been replicated with French listeners and French materials. There is good reason for this omission; the repertoire of available phonological structures simply forbids it. English-like stress (i.e., an opposition, fundamental to speech rhythm, between strong vowels with full vowel quality and weak 
vowels with neutral vowel quality) does not appear in French phonological structure. For the same reason that (as we pointed out in the introduction) syllabic segmentation could have been a universal segmentation procedure but stress-based segmentation could not, we were limited in the degree to which direct cross-linguistic comparisons were possible. We could test for the use of French-like syllabic segmentation in English because English (and indeed any other language) has syllables. But it was simply not possible to test in the same way for English-like stress-based segmentation in French.

The implication of this for our present studies with bilinguals is that it limits the degree to which we can replicate the effects of dominance which we observed in Experiments 1 and 2. Were it possible to carry out a cross-linguistic test of stress-based segmentation, we hypothesise that we would find the English-dominant group looking more flexible, more bilingual, in just the way the French-dominant group does with the test of syllabic segmentation; that is, we would predict that French-dominant bilinguals would not use stress-based segmentation but would resort with any input to the general procedure, while English-dominant bilinguals would use stress-based segmentation with English but abandon its use with French.

We very much regret that the phonologies of French and English make a cross-linguistic test impossible. Nevertheless, it is possible to undertake a within-language test which addresses the simple availability of stressbased segmentation to the two bilingual groups. That is, although it is impossible to test for stress-based segmentation with French materials, we can test for it with English materials alone. In Experiment 3, therefore, we replicated one of Cutler and Norris' experiments with FrenchEnglish bilinguals. Although a parallel test in French is impossible, the account we offered above would nevertheless predict an asymmetry between French-dominant and English-dominant bilinguals on English materials alone. If stress-based segmentation is a language-specific segmentation procedure, then English-dominant bilinguals should replicate the results of Cutler and Norris' original monolingual subjects, but Frenchdominant bilinguals should not.

\section{EXPERIMENT 3}

\section{Method}

Subjects. We traced and retested six subjects who had participated in Experiments 1 and 2. Of these, three (one English-dominant and two French-dominant) had originally been tested in Paris, the others (all French-dominant) in the UK. Thirteen further subjects were tested at the bilingual high school in London and at Cambridge University. The criteria for subject selection were as for Experiments 1 and 2. Sixteen of the 19 subjects had one French-speaking and one English-speaking parent. 
Language dominance was assessed by means of a questionnaire (for further details see Kearns, in preparation). The questionnaire included the "brain operation" question which we had used in Experiments 1 and 2, and the new subjects were classified as Frenchdominant or English-dominant according to their answers to this question. Of the 13 new subjects, nine were English-dominant and four French-dominant.

The data for one subject (French-dominant) were lost due to experimental malfunction. Three of the new high school subjects (two English-dominant, one French-dominant) failed to reach the $70 \%$ correct word detection criterion (used in the original study) for inclusion in the experiment: they missed 14,14, and 16 words out of 32, respectively. After exclusion of these subjects, we had data for eight English-dominant and seven French-dominant subjects.

Materials. To achieve strict comparability with previous results, we again used exactly the same recordings used in the predecessor study, which in this case was Experiment 3 of Cutler and Norris (1988).

There were two materials sets, each of which contained 105 nonsense bisyllables. Of these, 70 did not contain real words (e.g., bozzen, crenthish, grivelom, scrornive) and three were filler items. The remaining 32 experimental items all began with a real word. Half of the words had CVCC structure (mint, risk) while the other half were CVC (thin, kiss). The CVCC words were made into nonwords by the addition of a final VC, where the vowel could be either strong or weak (the weak vowel was always schwa); for mint and risk the stimuli were mintayf, mintef, riskeeb, riskeb. The CVC words were made into nonwords by the addition of CVC, where the VC was always the same as the VC used for the matched CVCC word, and the extra consonant was always the matched CVCC word's final consonant. Thus thin and kiss became thintayf, thintef, kiskeeb, and kiskeb.

Only one version of each word occurred in each materials set; word structure and type of ending were counterbalanced across materials sets. The words were spoken by a male speaker of British English. Further details and a complete list of the materials can be found in Cutler and Norris (1988).

Procedure. Subjects were tested individually. They were instructed that they would hear nonsense words and that they should press the response key whenever they heard a nonsense item beginning with a real English word. They should then say aloud the word they had detected. Five English-dominant and five French-dominant subjects heard Tape 1, and three English-dominant and two French-dominant subjects heard Tape 2.

Subjects' spoken responses were recorded and checked. If a subject spoke any word other than the intended word, the corresponding response was discarded from the RT analysis.

Response times were measured from a signal aligned with the burst of the stop consonant which was always the fourth phoneme in the CVCCVC. Timing and data collection were controlled by microcomputer.

Predictions. The results of the predecessor study with English monolinguals are shown in Figure 4. Response times to detect CVCC words were affected by the nature of the vowel in the following syllable--that is, mint was significantly harder to detect in mintayf than in mintef. However, there was no corresponding effect for the CVC control words-thin was detected with equal facility in thintayf and thintef.

Cutler and Norris explained this result in terms of segmentation procedures used by English listeners: a strong vowel triggers segmentation of the speech signal at the onset of its syllable. Thus mintayf is segmented min-tayf, which interferes with detection of the embedded word because detection will now require reassembly of speech material which has been divided by segmentation. No segmentation is triggered by a following weak vowel, therefore detection of mint in mintef is not inhibited. In the control condition, thintayf will likewise be segmented and thintef will not, but since the embedded word is not in this case divided by the segmentation, there will again be no inhibition. 


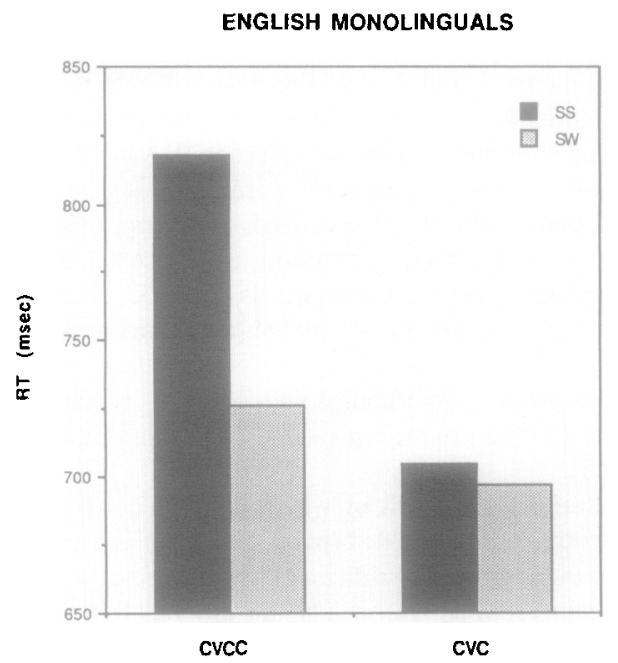

FIG. 4. Mean word detection response times (RT) by English monolinguals in a preceding study as a function of whether the second syllable of the nonsense word contained a strong (SS) or a weak (SW) vowel, and whether the embedded word ended in a cluster (CVCC) or a single consonant (CVC).

We predict that English-dominant subjects should show the same pattern of results as English monolinguals; thus their results should resemble those of Fig. 4. The Frenchdominant subjects, on the other hand, should not show this pattern.

The rationale for including CVC words as well as CVCC words in the predecessor study was that these words formed a control to test alternative explanations of the effect with CVCC words (established first in Experiment 1 of the predecessor study); among these explanations was one based on syllabic segmentation. Assuming that the syllable boundary in both mintayf and mintef occurs between the two medial consonants, then an account of Cutler and Norris' finding in terms of syllabic segmentation would seem to be ruled out (since the effects should be equal for both those items). However, some accounts of English syllable structure would allow the syllable boundary in mintef to occur after the medial cluster. On such an account, the results for CVCC words might have been explained in terms of syllabic segmentation. However, such an account would predict the reverse effect for CVC words, namely inhibition of detection of thin in thin-tef versus thin-tayf. Because no such reverse effect appeared (see Fig. 4), Cutler and Norris argued that their findings confirmed the conclusion of Cutler et al. (1986) that syllabic segmentation is not used by English listeners.

The inclusion of this condition nevertheless allows us to test for syllabic segmentation in the present study with bilinguals. Of course, the conflicting accounts of English syllable structure mean that the test is not as simple as it might have been. But each account makes a clear prediction. If the proper phonological account of English syllabification specifies that our materials be divided min-tayf, min-tef, thin-tayf, thin-tef, then subjects using syllabic segmentation will find word detection inhibited by both endings for CVCC words, but inhibited by neither ending for CVC words; thus there should be a main effect whereby CVC words are detected faster than CVCC words, but no effects of ending type. On the other hand, if our materials are properly divided min-tayf, mint-ef, thin-tayf, thint-ef, then subjects using syllabic segmentation will be inhibited by strong vowel endings for CVCC words 
but inhibited by weak vowel endings for CVC words-thus there should be an interaction between word structure and ending type.

Our prediction, of course, is that no subject will show evidence of syllabic segmentation. The English-dominant subjects will not show it because they do not command it, and the French-dominant subjects will not show it because, as Experiments 1 and 2 demonstrated, they have learned to inhibit its use with English-language input.

\section{Results}

In the predecessor study the responses for one set of items were discarded because of a miss rate greater than $50 \%$ for one member of the set $(n u m b)$. For the sake of comparability the responses to this set were also discarded from the present data (in fact, the word numb again had the highest miss rate of all words).

Figure 5 shows the mean response times (measured from the burst of the medial stop consonant) in each condition of Experiment 3, separately
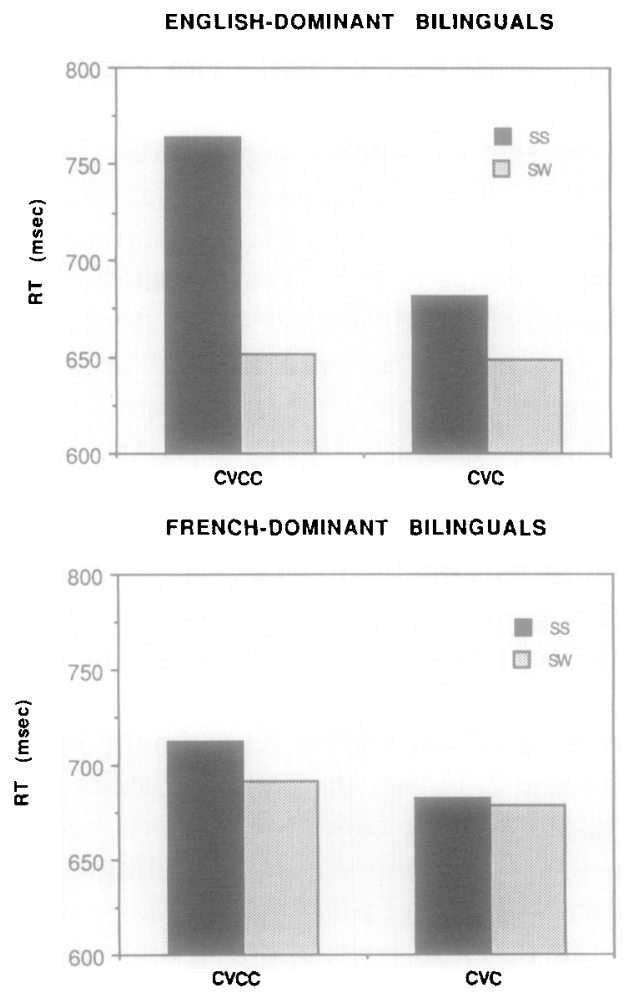

FIG. 5. Mean word detection response times (RT) in Experiment 3, separately for English-dominant and French-dominant bilinguals, as a function of whether the second syllable of the nonsense word contained a strong (SS) or a weak (SW) vowel, and whether the embedded word ended in a cluster (CVCC) or a single consonant (CVC). 
for English-dominant and French-dominant subjects. The results for the English-dominant subjects, as predicted, closely resemble the pattern shown in Fig. 4. Detection of CVCC words is significantly more difficult when the vowel in the ending is strong rather than weak $(t[7]=2.79, p<$ $.03)$. There is no significant difference for CVC words $(t<1)$. The results for French-dominant subjects, however, show no effects of ending type for either CVCC or CVC words ( $t<1$ in both cases). There is also no main effect of word structure for either subject group ( $t<1$ in both cases).

\section{Discussion}

The results of Experiment 3 showed, exactly as predicted, an asymmetry between the performance of English-dominant versus Frenchdominant bilinguals with English materials. English-dominant bilinguals replicated the pattern of results shown by English monolinguals and explained by Cutler and Norris (1988) as evidence of stress-based segmentation; French-dominant bilinguals did not show that pattern. Stressbased segmentation appears, therefore, not to be used by Frenchdominant bilinguals even where its use-with English materials-would be appropriate.

There was also no sign of syllabic segmentation by either group. The CVC control condition allowed a test of this; but neither group displayed either of the patterns of results which, as described above, could have been interpreted as evidence of syllabic segmentation; that is, for neither group was there a main effect of word structure, and for neither group was there a crossover interaction between word structure and ending type. Instead, the only significant difference of any kind was the effect of ending type, for CVCC words only, displayed by the English-dominant bilinguals-cxactly the effect which, with English monolinguals, provided evidence of stress-based segmentation. Our predictions for Experiment 3, based on the previous results from Experiments 1 and 2, are therefore confirmed: neither bilingual group shows syllabic segmentation with these materials, and only the English-dominant group shows stress-based segmentation.

However, as we pointed out above, Experiment 3 is a less perfect test than Experiments 1 and 2, in that there is no parallel study which we can run with French materials. We cannot, therefore, tell whether our additional prediction-that English-dominant bilinguals would abandon stress-based segmentation with French materials-would be supported. It should also be noted that the word-spotting task used in Experiment 3 taps into a different processing level than the syllable detection task used in Experiments 1 and 2; responses in the word-spotting task depend upon access of a lexical representation, whereas responding in the syllable detection task does not. However, there is a sense in which the precise 
nature of the task is quite irrelevant to our most central conclusion. All of the experiments which we have conducted were undertaken as comparison studies to previous investigations of speech recognition by monolinguals. There may well be debate about the interpretation of performance in tasks such as the two used here and in the predecessor studies, and the precise nature of the task is indeed relevant to this debate. But there is no doubt about the results of the predecessor studies; and given that the present study made use of the same experimental paradigms-indeed, the very same experimental recordings!-as the predecessor studies, there is no doubt about the comparison to be drawn between the new results and the old. French-dominant bilinguals show processing patterns which mimic those of French-speaking monolinguals; English-dominant bilinguals do not. English-dominant bilinguals, on the other hand, show processing patterns which mimic those of English-speaking monolinguals; French-dominant bilinguals do not.

\section{GENERAL DISCUSSION}

One of the hardest tasks that a listener has to deal with is segmenting continuous speech input into its constituent units. For the adult listener, a process of segmentation is compelled by the necessity of matching the input against lexical representations: due to memory limitations, these representations must be discrete, so that matching to them means that the continuous input first has to be apportioned into the appropriate constituent chunks. For the infant listener, however, the segmentation process is compelled by the necessity of compiling a lexicon, i.e., of discovering from scratch what the meaningful constituents of the speech input might be. With no existing lexicon and no speech experience to provide guidance, the infant's task is truly formidable. It is this task, we believe, which underlies the specific segmentation procedures which show up in our experiments.

How does the infant begin to deal with the segmentation problem? There is evidence that many-perhaps all-children experiment, if only briefly, with the possibility that segmentation could be avoided, i.e., that utterances could be processed as holistic units (Peters, 1977). Successful vocabulary growth, however, depends upon an analytic rather than a holistic approach. It is our view that the crucial intermediate process is the establishment of a form of prelexical representation, which can serve simultaneously as a vehicle for interpretation of the speech input, and a source of building materials for the construction of lexical access procedures (just such a model of lexical acquisition, using French as the target language and prelexical representations which are syllabic, has been instantiated by Mehler, Dupoux, and Segui, 1990). The analytic processes necessary for the development of prelexical, and indeed lexical, repre- 
sentations will make use of whatever aspects of the input they find useful. Linguistic rhythm, we believe, presents itself as both an extremely obvious and an easily exploitable property of the speech to which the infant is exposed.

It is known that infants are sensitive to linguistic rhythm-for instance, infants as young as four days old can discriminate a sequence of twosyllable words from a sequence of three-syllable words (Bijeljac-Babic, Bertoncini, \& Mehler, forthcoming). It is also apparently the case that speech to infants tends to exhibit more marked rhythmicity than spontaneous speech in general; many prosodic dimensions exhibit more marked structure in infant-directed speech than in adult-directed speech (Fernald and Simon, 1984), and included among the effects noted in English is more regular occurrence of primary stresses (Garnica, 1977). In other words, the criteria of exploitability and salience would seem to be fulfilled. Moreover, the constituent units of linguistic rhythm are salient to the infant. The syllable, for instance, is a unit to which infants exhibit sensitivity at a very early age-their discrimination for $\mathrm{CVC}$ sequences is very much better than for CCC sequences (Bertoncini \& Mehler, 1981). Thus the basis for some kind of rhythmically based segmentation procedure is given.

We suggest, therefore, that during language acquisition there occurs a process in which the infant exploits linguistic rhythm-the pattern of smallest occurring regularities in the input-to develop segmentation procedures. However, it would appear that only one such procedure may be developed. If the input at the crucial time exemplifies syllabic rhythm, a syllabic segmentation procedure will be developed; if the input displays a stress-based rhythmic structure, then the procedure which will be developed is stress-based segmentation.

Our discussion so far has contrasted only the two restricted segmentation procedures, namely, syllabic segmentation which is typical of French and segmentation at stressed syllables which is typical of English. Each of these procedures, it should be pointed out, has impressive support in the child language literature. Children learning English and other languages with stress do make use of stress rhythm in segmentation (Gerken, 1991; Gerken, Landau, \& Remez, 1990; Peters, 1985). Children learning French and other languages with syllable rhythm do use syllables in segmentation (Alegria, Pignot, \& Morais, 1982; Content, Kolinsky, Morais, \& Bertelson, 1986).

That there should be at least two possible restricted procedures, stressbased segmentation and syllabic segmentation, accords with linguistic thinking about the distribution of rhythmic structures across languages. Traditionally, phonologists (see e.g., Abercrombie, 1967) have distinguished between stress-timed languages (such as English), in which the 
basis of rhythm is the regular occurrence of stressed syllables, and syllable-timed languages (such as French), in which the basis of rhythm is the regular occurrence of syllables. This distinction is certainly an oversimplification, and a more sophisticated approach is provided by Dauer (1987), who proposes a continuum of rhythmic structure, with a language's place on the continuum being determined by its possession or not of a variety of features. Nevertheless, it is still the case that the distribution of languages on Dauer's continuum places English and French in opposite tails of the distribution. There are two basic kinds of rhythm which languages can have; therefore, it makes sense for there to be two types of rhythmically based segmentation procedure.

However, there are languages which have syllabic rhythm but also have stress contrasts, and evidence from Spanish and Catalan suggests that in such languages stress patterns can crucially determine whether or not syllabic segmentation is efficient (Sebastián-Gallés, Dupoux, Segui, \& Mehler, 1992). Moreover, there are other units which are held to be basic in language rhythm. The basis of rhythm in Japanese, for example, is a subsyllabic unit called the mora. The smallest regularly occurring unit in the speech input to an infant growing up in a Japanese environment would presumably be the mora. We are therefore reluctant to conclude at this point that the two procedures which our research has identified are the only two restricted rhythmically based segmentation procedures available for development by the human language acquisition system; more crosslinguistic studies involving languages with a maximally wide variety of rhythmic structures are clearly needed.

Finally, there remains one aspect of our data for which an explanation is lacking. The isolation of a meaningful pattern in our results was achieved by subdividing our bilingual group on the basis of their answer to our question: which language would our subjects most regret losing. We described their answers in terms of the concept of "language dominance." But this amounts to an operational definition rather than an account of how language dominance arises.

We confess that we began this study with the suspicion that mother's language might prove to be a crucial determining factor in perceptual performance. Indeed, in Experiments 1 and 2 our subanalysis by mother's language produced the nearest approximation to the results shown in the subanalysis by language dominance. However, the match was far from perfect, and our results do not provide any obvious alternative suggestion as to a causal factor in the determination of dominance. (We note, though, that we did not check with our bilinguals whether in each case the mother was indeed the primary caregiver-it is quite possible that in some cases she was not, and that in those cases dominance would after all reflect the language of the primary caregiver.) More extensive studies will be nec- 
essary to provide a full account of dominance. One limitation of the present study has been the difficulty of finding, within the basically monolingual communities in which we work, subjects who satisfy our (necessarily) strict criteria for a very high degree of bilingualism; more extensive studies would be most appropriately undertaken in a community where bilingualism is more common. However, in such communities the possibility exists that the two coexisting languages may have developed local forms which exhibit less difference (e.g., less rhythmic difference) than the same languages exhibit in the forms spoken by monolinguals; thus the study of bilinguals in such communities would have to be preceded by assessment of baseline processing performance in each language. (Ideally this assessment would involve testing of monolingual speakers; but in many bilingual communities, of course, monolingual speakers are as hard to find as bilinguals are in England and France!) Thus for our present study we had no option but to deal with the difficulty of locating subjects as best we could.

Although the provenance of language dominance remains obscure, its nature has been illuminated by our study. At the level of speech segmentation, there are procedures which are developed on the basis of languagespecific input features, and are thus restricted in their availability in that only speakers who were presented at the right time with the right kind of input can develop them. Beyond this, though, it would appear that only one such procedure of any one kind can be developed. Language dominance is fully correlated with which procedure is developed.

In the case of bilinguals the implications of this limitation are quite remarkable: there is only one restricted segmentation procedure possible no matter how many languages one knows. In other words, even bilinguals who are as bilingual as it is possible to be must function, at some level of their language processing, as nonbilinguals. The concept of language dominance implies inequality in even the most bilingual speakerone language, and only one, will be catered for by a segmentation procedure of the restricted kind.

This does not mean, we stress, that a bilingual's processing of nondominant language(s) is in any way imperfect. As we pointed out above, the restricted procedures are merely alternatives to the general procedures. The latter are developed by all speakers, monolingual, bilingual, or multilingual. In the case of speech segmentation, the restricted procedures exploit rhythmic probabilities to speed up segmentation and hence lexical access, while the general procedures also perform segmentation, possibly by exploiting universal rather than language-specific phonological characteristics (see Cutler, Mehler, Norris and Segui [1986] and Cutler, Norris and Williams [1987] for further discussion). A restricted segmentation procedure which exploits one type of linguistic rhythm will obviously be 
inefficient with another type. One aspect of bilingual proficiency, then, is learning to abandon the restricted procedure when it is inefficient and to invoke the general procedure in its place. Monolinguals, unable to process nonnative speech input as meaningful language, cannot learn to abandon their one procedure; bilinguals, with their ability to process meaning in more than one phonological form, can quickly recognize when their particular procedure is functioning inefficiently and abandon it.

Our results, then, have told us something about the nature of segmentation procedures and also something about bilingualism. Rhythmically based segmentation procedures are not only language-specific and restricted in their availability, but also, it scems, mutually exclusive. In some aspects of their processing, therefore, bilinguals as a consequence of this limitation may be functionally monolingual.

\section{REFERENCES}

Abercrombie, D. (1967). Elements of General Phonetics. Edinburgh: Edinburgh University Press.

Alegria, J., Pignot, E., \& Morais, J. (1982). Phonetic analysis of speech and memory codes in beginning readers. Memory \& Cognition, 10, 451-456.

Baetens Beardsmore, H. (1982). Bilingualism: Basic Principles. Clevedon: Tieto.

Bertoncini J., \& Mehler J. (1981). Syllables as units in infant speech perception. Infant Behavior and Development, 4, 247-260.

Bijeljac-Babic, R., Bertoncini, J., \& Mehler, J. (forthcoming). Discrimination of multisyllabic CVs by newborns.

Content, A., Kolinsky, R., Morais, J., \& Bertelson, P. (1986). Phonetic segmentation in prereaders: Effect of corrective information. Journal of Experimental Child Psychology, 42, 49-72.

Cutler, A., \& Butterfield, S. (1992). Rhythmic cues to speech segmentation: Evidence from juncture misperception. Journal of Memory and Language, 31, 218-236.

Cutler, A., \& Carter, D. M. (1987). The predominance of strong initial syllables in the English vocabulary. Computer Speech and Language, 2, 133-142.

Cutler, A., Mehler, J., Norris, D. G., \& Segui, J. (1986). The syllable's differing role in the segmentation of French and English. Journal of Memory and Language, 25, 385-400.

Cutler, A., \& Norris, D. G. (1988). The role of strong syllables in segmentation for lexical access. Journal of Experimental Psychology: Human Perception and Performance, 14, 113-121.

Cutler, A., Norris, D. G., \& Williams, J. N. (1987). A note on the role of phonological expectations in speech segmentation. Journal of Memory and Language, 26, 480-487.

Dauer, R. M. (1987). Phonetic and phonological components of language rhythm. Proceedings of the 11th International Congress of Phonetic Sciences, Tallinn; 5, 447-450.

Fernald, A., \& Simon, T. (1984). Expanded intonation contours in mothers' speech to newborns. Developmental Psychology, 20, 104-113.

Garnica, O. (1977). Some prosodic and paralinguistic features of speech to young children. In C. E. Snow \& C. A. Ferguson (Eds.), Talking to Children: Language Input and Acquisition. (pp. 63-88.) Cambridge: Cambridge University Press.

Gerken, L. (1991). The metrical basis for children's subjectless sentences. Journal of Memory and Language, 30, 431-451.

Gerken, L., Landau, B., \& Remez, R. E. (1990). Function morphemes in young children's speech perception and production. Developmental Psychology, 26, 204-216. 
Grosjean, F. (1982). Life with Two Languages. Cambridge, MA: Harvard University Press.

Grosjean, F. (1989). Neurolinguists, beware! The bilingual is not two monolinguals in one person. Brain \& Language, 36, 3-15.

Kearns, R. K. (in preparation). Bilingual language processing. $\mathrm{PhD}$. Thesis, University of Cambridge.

Mehler, J., Dommergues, J.-Y., Frauenfelder, U., \& Segui, J. (1981). The syllable's role in speech segmentation. Journal of Verbal Learning and Verbal Behaviour, 20, 298-305.

Mehler, J., Dupoux, E., \& Segui, J. (1990). Constraining models in lexical access: The onset of word recognition. In G. T. M. Altmann (Ed.), Cognitive Models of Speech Processing: Psycholinguistic and Computational Perspectives. (pp. 236-262.) Cambridge, MA: MIT Press.

Peters, A. M. (1977). Language learning strategies: Does the whole equal the sum of the parts? Language, 53, 560-573.

Peters, A. M. (1985). Language segmentation: Operating principles for the perception and analysis of language. In D. I. Slobin (Ed.) The Crosslinguistic Study of Language Acquisition. Vol. 2: Theoretical Issues. (pp. 1029-1067.) Hillsdale, NJ: Erlbaum.

Sebastián-Gallés, N., Dupoux, E., Segui, J., \& Mehler, J. (1992). Contrasting syllabic effects in Catalan and Spanish: The role of stress. Journal of Memory and Language, 31, 18-32.

Thiery, C. (1976). Le bilinguisme vrai. Etudes de linguistique appliquée, 24, 52-63.

(Accepted September 17, 1991) 